\title{
Viral Surveillance of Children with Acute Respiratory Infection in Two Main Hospitals in Northern Jordan, Irbid, during Winter of 2016
}

\author{
Samah Awad ${ }^{1}$ Yousef Khader ${ }^{2}$ Moa'th Mansi ${ }^{1}$ \\ Ruba Khasawneh ${ }^{3}$ \\ ${ }^{1}$ Department of Pediatrics and Neonatology, Faculty of Medicine, \\ King Abdullah University Hospital, Jordan University of Science and \\ Technology, Irbid, Jordan \\ 2 Department of Public Health and Community Medicine, Faculty of \\ Medicine, Jordan University of Science and Technology, Irbid, Jordan \\ ${ }^{3}$ Department of Diagnostic Radiology and Nuclear Medicine, Faculty \\ of Medicine, King Abdullah University Hospital, Jordan University of \\ Science and Technology, Irbid, Jordan
}

Dawood Yusef ${ }^{1}$ Salah Alawadin ${ }^{1}$ Walaa Qudah ${ }^{1}$

\begin{abstract}
Address for correspondence Samah Awad, MBBS, Department of Pediatrics and Neonatology, Faculty of Medicine, King Abdullah University Hospital, Jordan University of Science and Technology, P.O. Box 3030, Irbid 22110, Jordan (e-mail: smawad@just.edu.jo).
\end{abstract}

J Pediatr Infect Dis 2020;15:1-10.

\begin{abstract}
Keywords

- acute respiratory infection

- children

- Jordan

- respiratory syncytial virus

- RT-PCR

Acute lower respiratory infection (ALRI) is a major cause of morbidity and mortality worldwide. Data regarding the etiology of acute respiratory infection (ARI) is scarce in developing countries. The aim of this study was to identify the viral etiology of ARI/ALRI in hospitalized children and factors associated with increased length of stay (LoS) and severe disease presentation in Northern Jordan. This was a prospective viral surveillance study using real-time reverse transcriptase-polymerase chain reaction in children younger than 5 years admitted with ARI to two main hospitals in Northern Jordan during the winter of 2016. Nasopharyngeal swabs were obtained and tested for respiratory syncytial virus (RSV) and other viruses. Demographic and clinical characteristics of RSV-positive patients were compared with those of RSV-negative patients. There were 479 patients hospitalized with ARI. Their mean age (standard deviation) was 10.4 (11.6) months. 53.9\% tested positive for at least one virus, with RSV being the most commonly detected virus (34\%). Compared with RSV-negative patients, RSV-positive patients were younger, more likely to have chronic lung disease, and more likely to present with cough, rhinorrhea, difficulty in breathing, retraction, flaring, grunting, wheezing, and a higher respiratory rate. Prematurity, presence of a chronic illness, oxygen saturation $<90 \%$, and atelectasis and consolidation on chest $\mathrm{X}$-rays were significantly associated with an increased mean LoS. Patients with a history of prematurity had higher risk of severe disease (odds ratio $=2.6$; $95 \%$ confidence interval: 1.5, 4.7; $p=0.001$ ). Compared with patients 6 months old and younger, patients aged 6.1 to 12 months were less likely to have severe disease. Human metapneumovirus (HMPV)-positive ALRI was associated with increased odds of severe disease. Viruses are recognized as etiological agent of ARI/ALRI-associated morbidity in developing countries that need more attention and implementation of targeted strategies for prevention and detection. HMPV can be a cause of severe ALRI.
\end{abstract}

received

December 9, 2018

accepted after revision

May 20, 2019

published online

July 4, 2019
Copyright @ 2020 by Georg Thieme

Verlag KG, Stuttgart . New York
DOI https://doi.org/

10.1055/s-0039-1692972. ISSN $1305-7707$. 


\section{Introduction}

Acute lower respiratory infection (ALRI) is a major cause of morbidity and mortality worldwide in children younger than 5 years. ${ }^{1}$ Respiratory syncytial virus (RSV) is the most common viral pathogen causing acute respiratory infection (ARI) in young children globally and is an important cause of ARIrelated hospitalization and death, especially in developing countries. ${ }^{2,3}$ It was estimated globally in 2015 , that 33.1 million cases of RSV-ALRI resulted in approximately 3.2 million hospital admissions and 59,600 in-hospital deaths in children younger than 5 years. ${ }^{4}$ There are other viruses associated with ALRI in children younger than 5 years including human metapneumovirus (HMPV), rhinovirus, adenovirus, bocavirus, coronavirus, parainfluenza virus, and influenza virus., ${ }^{5,6}$ All these viruses, except for influenza virus, are more likely to occur in children younger than 5years in the Eastern Mediterranean region than in older children and adults. ${ }^{7}$

Data about the incidence and frequency of common viruses causing ARI/ALRI in young children and the risk factors for the severe presentation of ARI/ALRI in developing countries, particularly in the Middle East, are scarce. ${ }^{8-10}$ Therefore, there are limitations affecting the estimation of the burden of ARI/ALRI due to viruses on health resources and the implementation of strategies for prevention such as RSV prophylaxis ${ }^{11}$ and a future RSV vaccine. ${ }^{12}$

Methods of detecting RSV and other viruses causing ARI/ALRI include antigen detection, cell culture, serology testing, and reverse transcriptase-polymerase chain reaction (RT-PCR), with the latter having the highest detection sensitivity among other testing modalities. ${ }^{13}$ The use of RT-PCR to detect the viral pathogens causing ARI in young children has been limited in Jordan due to its high cost. Few studies have been conducted in Jordan to detect the etiology of ARI using RT-PCR for diagnostic testing. Most of the available studies tested children for only one virus. ${ }^{14-17}$

Halasa et al studied the viral etiology of ARI/ALRI in hospitalized children younger than 2 years in Amman, the capital city of Jordan, and RSV was the most commonly detected virus. ${ }^{18}$ The peak months of RSV infection were reported to be mainly January and February. ${ }^{18}$ However, RSV prophylaxis is not the standard of care for high-risk groups of children who are vulnerable for RSV infection in Jordan; it is not available in government or public hospitals nor it is covered by insurance. Therefore, further studies in Jordan are warranted to highlight the burden of viral ARI/ALRI caused by RSV to convince policy makers of the necessity of prevention. In addition, identifying the etiology and the frequency of other viruses causing ARI/ALRI can guide practitioners in optimizing the management of patients with ARI/ALRI, such as avoiding the overuse of antibiotics, especially given that viral testing is not a routine practice in diagnosing children admitted to the hospitals with ARI/ALRI in Jordan. Identifying the risk factors for hospital admission and severe disease in young children with ARI/ALRI is vital to accurately estimating the morbidity and mortality associated with ARI/ALRI and thus the burden imposed on individuals and health system in Jordan.
The objectives of this study were to identify the viruses causing ARI/ALRI using real-time RT-PCR in children younger than 5 years who were hospitalized during winter season of 2016 in two main hospitals in Irbid, Northern Jordan, which is in a different geographic area and has different population characteristics from Amman and to determine demographic and clinical characteristics of patients admitted with ARI/ALRI and the risk factors for increased length of hospital stay (LoS) and severe disease.

\section{Methods}

\section{Study Design and Setting}

This was a prospective viral surveillance study of children younger than 5 years diagnosed with ARI who were admitted to Princess Rahmah Hospital (PRH, the main community children's hospital in Northern Jordan that is run by the Ministry of Health) and King Abdullah University Hospital (KAUH, the only university-based hospital and tertiary referral health center in Irbid, Northern Jordan). The study was conducted over a 3-month period from January 15 to April 15, 2016. Children were enrolled 7 days a week within 48 hours of admission. The purpose and methodology of the study were discussed with parents, and informed consent was obtained prior to enrollment. All children younger than 5 who were hospitalized with fever $\left(>100.4^{\circ} \mathrm{F} / 38.0^{\circ} \mathrm{C}\right)$ and respiratory symptoms or respiratory symptoms alone in both hospitals and diagnosed with ARI were included. These patients were classified as having ALRI if they presented with cough or difficulty breathing in addition to tachypnea or any other symptom or sign indicative of lower respiratory tract infection, including retractions, flaring, grunting, wheezing, and crackles. Severe ALRI was defined as the presence of cough or difficulty breathing in addition to one or more of the following: retractions, nasal flaring, grunting, oxygen saturation $\left(\mathrm{SpO}_{2}\right)<90 \%$ at room air, altered mental status, intensive care unit (ICU) admission, or patient death. ${ }^{19}$

\section{Viral Detection}

Nasopharyngeal sampling was performed with diagnostic swabs and transport medium (Puritan UniTranz-RT Transport System with PurFlock Ultra swab [25-3317-U]; UT-317). Samples were stored at $-80^{\circ} \mathrm{C}$ until they were tested with real-time RT-PCR for viruses using a multiplex identification kit (AmpliSens ARVI-screen-FRT PCR kit). ${ }^{20}$ The viruses identified were RSV, HMPV, human rhinovirus (HRV), human adenovirus (HAdV), human bocavirus (HBoV), $\alpha$ corona viruses $229 \mathrm{E}$ and NL63 (HCoV1), $\beta$ corona viruses OC43 and HKU1 (HCoV2), and human parainfluenza viruses (HPIV) 1-4.

\section{Demographic and Clinical Data Collection}

Data were collected from parents through face-to-face interviews. Questionnaires were also completed to collect data on patient age, gender, gestational age, birth weight, chronic lung disease of prematurity, breast feeding history, daycare attendance, the presence of siblings older and younger than 5 years, 
smoking exposure, antibiotic use prior to hospitalization, and the presence of a chronic illness, such as congenital heart disease, neuromuscular, neurological, cerebral palsy, seizure disorder, developmental delay, growth retardation, down syndrome, anatomical lung problem, cystic fibrosis (CF), asthma, hematological disease, renal, and metabolic diseases. Prematurity was defined as gestational age $<37$ weeks, ${ }^{21}$ and low birth weight was defined as birth weight $<2.5 \mathrm{~kg}$. ${ }^{22}$ The symptoms and physical examination findings at the time of presentation, including $\mathrm{SpO}_{2}$ readings, were recorded. Axillary temperature was measured in all patients. Tachypnea was defined as a respiratory rate $\geq 60$ /minute for infants younger than 2 months, $\geq 50 /$ minute for infants 2 to 12 months old, and $\geq 40$ /minute for children 12 to 60 months old. ${ }^{19}$ Medical charts were reviewed to retrieve the LoS, medications used, leukocyte counts, final diagnoses, and survival outcomes. The chest radiograph of each patient was read by a pediatric radiologist who was blinded to the clinical data and viral testing results.

\section{Statistical Analysis}

Data are described using means and standard deviation (SD) for continuous variables and frequencies and percentages for categorical variables. The frequency of RSV and other viruses causing ARI/ALRI in children younger than 5 years are presented as frequency distributions. The relevant demographic and clinical characteristics of RSV-positive patients were compared with those of RSV-negative patients using the chi-square test. Multivariate analysis of factors associated with LoS in the whole cohort was conducted using the general linear model procedure. Risk factors for severe disease presentation and mortality were analyzed with binary logistic regression analysis. The variables were included in the model stepwise and those with $p<0.10$ in the univariate analysis were included in the multivariate model of risk factors. Possible associated factors were examined for evidence of multicollinearity, which was reflected by either the changes in the direction of effect between the univariate and multivariate analysis, or implausible standard errors for a particular variable. A $p$-value of $<0.05$ was considered statistically significant. Analysis was performed using IBM SPSS 20 (SPSS Inc., Chicago, IL).

\section{Results}

\section{Study Population}

There were 485 patients initially recruited into this study, 6 were excluded after a final diagnosis of meningitis $(n=2)$, urinary tract infection $(n=2)$, or gastroenteritis $(n=2)$. In total, 479 patients were diagnosed with ARI (302 males [63\%] and 177 females [37\%]). Their ages ranged between 1 and 60 months, with a mean (SD) age of 10.4 (11.6) months. The majority (89.8\%) was aged $\leq 24$ months, $72.7 \%$ were aged $\leq 12$ months, and approximately one-half (52.6\%) were aged $\leq 6$ months. Of all patients, $15.0 \%$ were premature (specifically 29-36 weeks), $20.5 \%$ had a history of low birth weight, and $4.4 \%$ had chronic lung disease. Among all the patients, only $29.6 \%$ were exclusively breastfed, $7.3 \%$ attended daycare, $81.6 \%$ had at least one sibling, 75.6\% were exposed to smoke at home, $50.5 \%$ got antibiotics prior to hospitalization, and $84.6 \%$ received antibiotics during hospitalization. A chronic illness presented in $15.9 \%$ of patients. The diagnosis upon admission was bronchiolitis in $49.7 \%$, bronchopneumonia in $23.0 \%$, and pneumonia in $15.2 \%$ of the children. The remaining children had other diagnoses, including asthma exacerbation, rule out sepsis, croup, pertussis-like illness, CF exacerbation, and fever for investigation. The mean (SD) LoS was 3.56 (2.4) days. Three patients died; one was positive for HMPV, and the other two were not positive for any of the tested viruses (bacterial cultures were negative in all patients who died).

\section{Viral Detection}

A virus was detected in $53.9 \%$ of the children. RSV was the most commonly detected virus (34.0\%), followed by HRV (15.7\%), HMPV (6.9\%), and HAdV (4.2\%). Less common viruses were $\mathrm{HBoV}$ (2.5\%), HCoV2 (1.5\%), HPIV1 (1.5\%), HPIV2,3,4 (0.6\%), and HCoV1 (0.4\%) (-Fig. 1). Of the 163 RSV-positive children, $27.6 \%$ were positive for one or two other viruses.

\section{Characteristics of RSV-Positive ARI Patients Compared with Those of RSV-Negative ARI Patients}

- Table 1 shows the relevant demographic and clinical characteristics of RSV-positive patients compared with RSV-negative patients. In comparison to RSV-negative patients, RSV-positive children were significantly younger $(p=0.030)$ and more likely to have chronic lung disease ( 7.4 vs. $2.8 \% ; p=0.022$ ). Compared with RSV-negative children, RSV-positive children were more likely to present with cough (97.5 vs. $92.1 \%, p=0.018$ ), rhinorrhea (63.8 vs. $51.9 \%$; $p=0.013$ ), difficulty breathing (93.3 vs. $83.5 \% ; p=0.003$ ), retraction ( $28.8 \%$ vs. $20.6 \%$; $p=0.043$ ), flaring (14.1 vs. $7.0 \%$; $p=0.011$ ), grunting ( 7.4 vs. $2.5 \% ; p=0.004$ ), and wheezing on auscultation ( 39.9 vs. $26.9 \% ; p=0.004$ ). The mean respiratory rate was significantly higher in RSV-positive patients than in RSV-negative (55.0 vs. $51.4 ; p=0.001$ ). Interstitial markings on X-rays were more pronounced in RSV-positive patients than in RSV-negative patients ( 40.3 vs. $31.0 \% ; p=0.047$ ). The two study groups were not significantly different in terms of ICU admission, death, and severe ALRI.

\section{Clinical Characteristics of HRV and HMPV}

Comparison among RSV, HRV, and HMPV positive patients revealed high grade fever $>38^{\circ} \mathrm{C}$ affecting RSV-positive children more than HRV-positive $(p=0.015)$. Leukocytosis was observed in RSV- and HRV-infected patients more than HMPV ( $p=0.021)$. HMPV was positive in one of the death cases, neither RSV nor HRV were detected in any patients who died $(p=0.04)$. No differences were noted in other clinical symptoms or signs, LoS, and risk for ALRI among the three viruses.

\section{Coinfection with RSV}

Coinfection with at least one virus was observed in 45 (27.6\%) of the RSV-positive patients. Out of the 45 patients infected with RSV, 23 (14.1\%) were coinfected with HRV, 10 
4 Viral Surveillance of Children with Acute Respiratory Infection Awad et al.

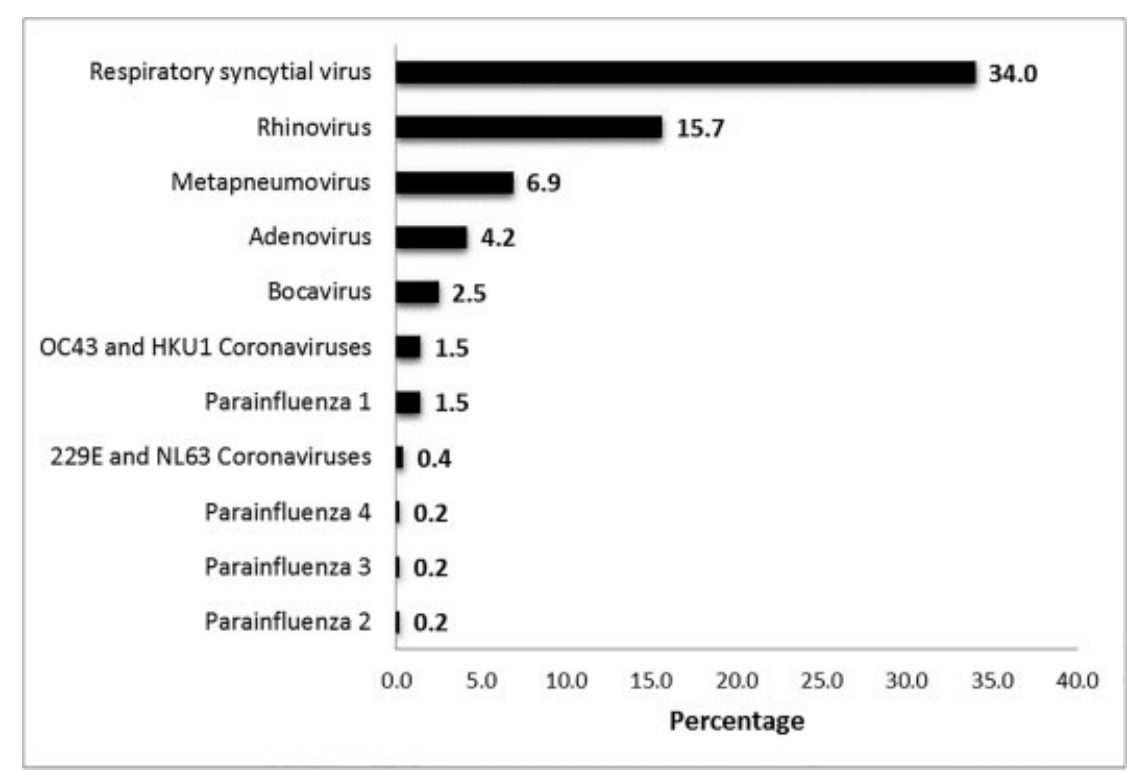

Fig. 1 Frequency of viruses detected in hospitalized patients with acute respiratory infection (ARI).

Table 1 The relevant demographic and clinical characteristics of RSV-positive patients compared with RSV-negative patients

\begin{tabular}{|c|c|c|c|c|c|}
\hline \multirow[t]{3}{*}{ Variable } & \multirow{2}{*}{\multicolumn{2}{|c|}{$\begin{array}{l}\text { RSV-negative patients } \\
n=316(66 \%)\end{array}$}} & \multirow{2}{*}{\multicolumn{2}{|c|}{$\begin{array}{l}\text { RSV-positive patients } \\
n=163(34 \%)\end{array}$}} & \multirow[t]{3}{*}{$p$-Value ${ }^{a}$} \\
\hline & & & & & \\
\hline & $n$ & $\%$ & $n$ & $\%$ & \\
\hline Age (mo) & & & & & 0.03 \\
\hline$\leq 6$ & 161 & 50.9 & 91 & 55.8 & \\
\hline $6.1-12$ & 56 & 17.7 & 40 & 24.5 & \\
\hline $12.1-24$ & 61 & 19.3 & 21 & 12.9 & \\
\hline$>24$ & 38 & 12.0 & 11 & 6.7 & \\
\hline Gender & & & & & 0.341 \\
\hline Male & 204 & 64.6 & 98 & 60.1 & \\
\hline Female & 112 & 35.4 & 65 & 39.9 & \\
\hline Premature & 46 & 14.6 & 26 & 16.0 & 0.686 \\
\hline Low birth weight & 69 & 22.3 & 29 & 18.0 & 0.274 \\
\hline Chronic lung disease & 9 & 2.8 & 12 & 7.4 & 0.022 \\
\hline Breastfeeding & 225 & 71.2 & 124 & 76.1 & 0.304 \\
\hline Daycare & 21 & 6.6 & 14 & 8.6 & 0.439 \\
\hline Siblings below 5 years old & 186 & 58.9 & 88 & 54.0 & 0.307 \\
\hline Siblings 5 years or older & 161 & 50.9 & 84 & 51.5 & 0.904 \\
\hline Smoking exposure & 246 & 77.8 & 116 & 71.2 & 0.107 \\
\hline Having chronic disease & 50 & 15.8 & 26 & 16.0 & 0.971 \\
\hline Family history of atopy & 99 & 31.3 & 58 & 35.6 & 0.347 \\
\hline Antibiotics prior to hospitalization & 165 & 52.4 & 77 & 47.5 & 0.316 \\
\hline Presenting symptoms & & & & & \\
\hline Fever $>38^{\circ} \mathrm{C}$ (high grade) & 132 & 41.8 & 72 & 44.2 & 0.615 \\
\hline Cough & 291 & 92.1 & 159 & 97.5 & 0.018 \\
\hline Wheezing & 141 & 44.6 & 78 & 47.9 & 0.501 \\
\hline Rhinorrhea & 164 & 51.9 & 104 & 63.8 & 0.013 \\
\hline
\end{tabular}


Table 1 (Continued)

\begin{tabular}{|c|c|c|c|c|c|}
\hline \multirow[t]{3}{*}{ Variable } & \multirow{2}{*}{\multicolumn{2}{|c|}{$\begin{array}{l}\text { RSV-negative patients } \\
n=316(66 \%)\end{array}$}} & \multirow{2}{*}{\multicolumn{2}{|c|}{$\begin{array}{l}\text { RSV-positive patients } \\
n=163(34 \%)\end{array}$}} & \multirow[t]{3}{*}{$p$-Value ${ }^{a}$} \\
\hline & & & & & \\
\hline & $n$ & $\%$ & $n$ & $\%$ & \\
\hline Apnea & 38 & 12.0 & 23 & 14.1 & 0.517 \\
\hline Difficulty breathing & 264 & 83.5 & 152 & 93.3 & 0.003 \\
\hline Cyanosis & 86 & 27.2 & 51 & 31.3 & 0.35 \\
\hline Decreased appetite & 276 & 87.3 & 141 & 86.5 & 0.796 \\
\hline Hypoactivity & 257 & 81.3 & 143 & 87.7 & 0.074 \\
\hline Vomiting & 67 & 21.3 & 46 & 28.2 & 0.090 \\
\hline Diarrhea & 38 & 12.0 & 19 & 11.7 & 0.906 \\
\hline Altered mental status & 12 & 3.8 & 4 & 2.5 & 0.438 \\
\hline \multicolumn{6}{|l|}{ Presenting signs } \\
\hline Tachypnea & 242 & 76.6 & 137 & 84.0 & 0.057 \\
\hline Respiratory rate, mean (SD) & $51.4(11.2)$ & & $55.0(10.5)$ & & 0.001 \\
\hline $\mathrm{SpO}_{2}$ & & & & & 0.061 \\
\hline$>94$ & 278 & 88.0 & 131 & 80.4 & \\
\hline $90-94$ & 9 & 2.8 & 12 & 7.4 & \\
\hline$<90$ & 22 & 7.0 & 17 & 10.4 & \\
\hline Retractions & 65 & 20.6 & 47 & 28.8 & 0.043 \\
\hline Flaring & 22 & 7.0 & 23 & 14.1 & 0.011 \\
\hline Grunting & 8 & 2.5 & 12 & 7.4 & 0.012 \\
\hline Wheezing & 85 & 26.9 & 65 & 39.9 & 0.004 \\
\hline Crackles & 198 & 62.7 & 107 & 65.6 & 0.52 \\
\hline \multicolumn{6}{|l|}{ Chest X-ray findings } \\
\hline Interstitial markings & 95 & 31.0 & 64 & 40.3 & 0.047 \\
\hline Hyperinflation & 61 & 19.9 & 43 & 27.0 & 0.081 \\
\hline Atelectasis & 36 & 11.8 & 29 & 18.2 & 0.056 \\
\hline Peribronchial thickening & 101 & 33.0 & 62 & 39.0 & 0.199 \\
\hline Consolidation & 63 & 20.6 & 27 & 17.0 & 0.35 \\
\hline Normal X-ray findings & 125 & 40.8 & 57 & 35.8 & 0.295 \\
\hline Leukocytosis & 83 & 26.7 & 43 & 26.5 & 0.973 \\
\hline \multicolumn{6}{|l|}{ Outcomes } \\
\hline ICU admission & 36 & 11.4 & 13 & 8.0 & 0.242 \\
\hline Death & 3 & 0.9 & 0 & 0.0 & 0.212 \\
\hline Length of stay, mean (SD) & $3.6(2.5)$ & & $3.5(2.2)$ & & 0.635 \\
\hline Severity & & & & & 0.144 \\
\hline Not severe & 216 & 70.6 & 103 & 64.0 & \\
\hline Severe & 90 & 29.4 & 58 & 36.0 & \\
\hline
\end{tabular}

Abbreviations: ICU, intensive care unit; RSV, respiratory syncytial virus; SD, standard deviation; $\mathrm{SpO}_{2}$, oxygen saturation.

Note: The demographic and clinical characteristics of RSV-positive patients were compared with those of RSV-negative patients using the chi-square test. A $p$-value of $<0.05$ was considered statistically significant.

${ }^{a}$ Value in bold is statistically significant ( $p$-value $\left.<0.05\right)$.

(6.1\%) with HMPV, 6 (3.7\%) with HBoV, 3 (1.8\%) with HAdV, 5 (3\%) with HPIV (3 with HPIV1, 1 with HPIV3, and 1 with HPIV4), and 1 with HCoV2. The most frequent triple infection in RSV-positive patients was the coexistence of RSV, HRV, and HMPV $(23,14 \%)$. When patients coinfected with HRV or HMPV were compared with those infected with RSV alone with regard to the risks of increased LoS, the severity of ALRI, and ICU admission, the only significant finding was that 
6 Viral Surveillance of Children with Acute Respiratory Infection Awad et al.

RSV-positive patients had a higher risk of ICU admission than those infected with both RSV and HMPV $(p=0.008)$.

\section{Clinical Characteristics of Children with Lower Respiratory Tract Infection (ALRI)}

In total, 463 (96.7\%) of 479 children met the criteria for ALRI. Of the 479 patients, 161 (33.6\%) had RSV-positive ALRI, 302 (63\%) had RSV-negative ALRI, and 16 (3.3\%) did not have
ALRI. - Table 2 shows the characteristics of patients with RSV-positive ALRI compared with those with RSV-negative ALRI. The two groups differ markedly in some presenting symptoms. RSV-positive ALRI were more likely to be younger, have chronic lung disease, and present with cough, rhinorrhea, difficulty breathing, grunting, wheezing, and a higher respiratory rate than RSV-negative ALRI.

Table 2 Characteristics of patients with RSV-positive ALRI compared with those of patients with RSV-negative ALRI

\begin{tabular}{|c|c|c|c|c|c|}
\hline \multirow[t]{2}{*}{ Variable } & \multicolumn{2}{|c|}{ RSV-negative ALRI } & \multicolumn{2}{|c|}{ RSV-positive ALRI } & \multirow[t]{2}{*}{$p$-Value ${ }^{a}$} \\
\hline & $n$ & $\%$ & $n$ & $\%$ & \\
\hline Age (mo) & & & & & 0.023 \\
\hline$\leq 6$ & 149 & 49.3 & 90 & 55.9 & \\
\hline $6.1-12$ & 56 & 18.5 & 40 & 24.8 & \\
\hline $12.1-24$ & 59 & 19.5 & 21 & 13 & \\
\hline$>24$ & 38 & 12.6 & 10 & 6.2 & \\
\hline Gender & & & & & 0.574 \\
\hline Male & 190 & 62.9 & 97 & 60.2 & \\
\hline Female & 112 & 37.1 & 64 & 39.8 & \\
\hline Premature & 44 & 14.6 & 25 & 15.5 & 0.783 \\
\hline Low birth weight & 69 & 23.4 & 28 & 17.6 & 0.152 \\
\hline Chronic lung disease & 9 & 3 & 12 & 7.5 & 0.028 \\
\hline Breastfeeding & 217 & 71.9 & 122 & 75.8 & 0.364 \\
\hline Daycare & 21 & 7 & 13 & 8.1 & 0.660 \\
\hline Siblings under $5 \mathrm{y}$ & 176 & 58.3 & 86 & 53.4 & 0.326 \\
\hline Siblings 5 y or older & 152 & 50.3 & 83 & 51.6 & 0.845 \\
\hline Smoking exposure & 237 & 78.5 & 116 & 72 & 0.122 \\
\hline Having chronic disease & 48 & 15.9 & 26 & 16.1 & 0.943 \\
\hline Family history of atopy & 93 & 30.8 & 58 & 36 & 0.253 \\
\hline Antibiotic prior hospitalization & 159 & 52.6 & 76 & 47.2 & 0.264 \\
\hline \multicolumn{6}{|l|}{ Presenting symptoms } \\
\hline Fever $>38^{\circ} \mathrm{C}$ (high grade) & 120 & 39.7 & 70 & 43.5 & 0.436 \\
\hline Cough & 285 & 94.4 & 159 & 98.8 & 0.023 \\
\hline Wheezing & 141 & 46.7 & 78 & 48.4 & 0.718 \\
\hline Rhinorrhea & 162 & 53.6 & 103 & 64.0 & 0.032 \\
\hline Apnea & 23 & 14.3 & 38 & 12.6 & 0.606 \\
\hline Difficulty breathing & 264 & 87.4 & 152 & 94.4 & 0.018 \\
\hline Cyanosis & 84 & 27.8 & 51 & 31.7 & 0.384 \\
\hline Decreased appetite & 263 & 87.1 & 140 & 87.0 & 0.968 \\
\hline Hypoactivity & 243 & 80.5 & 141 & 87.6 & 0.053 \\
\hline Vomiting & 64 & 21.3 & 45 & 28.0 & 0.107 \\
\hline Diarrhea & 34 & 11.3 & 19 & 11.8 & 0.861 \\
\hline Altered mental status & 12 & 4 & 4 & 2.5 & 0.403 \\
\hline \multicolumn{6}{|l|}{ Presenting signs } \\
\hline Tachypnea & 235 & 77.8 & 137 & 85.1 & 0.061 \\
\hline Respiratory rate (SD) & \multicolumn{2}{|c|}{$51.6(11.2)$} & \multicolumn{2}{|c|}{$55.3(10.2)$} & 0.001 \\
\hline $\mathrm{SpO}_{2}$ & & & & & 0.081 \\
\hline$>94$ & 264 & 87.4 & 129 & 80.1 & \\
\hline
\end{tabular}


Table 2 (Continued)

\begin{tabular}{|c|c|c|c|c|c|}
\hline \multirow[t]{2}{*}{ Variable } & \multicolumn{2}{|c|}{ RSV-negative ALRI } & \multicolumn{2}{|c|}{ RSV-positive ALRI } & \multirow[t]{2}{*}{$p$-Value ${ }^{a}$} \\
\hline & $n$ & $\%$ & $n$ & $\%$ & \\
\hline $90-94$ & 9 & 3 & 12 & 7.5 & \\
\hline$<90$ & 22 & 7.3 & 17 & 10.6 & \\
\hline Retractions & 65 & 21.5 & 47 & 29.2 & 0.066 \\
\hline Flaring & 22 & 7.3 & 23 & 14.3 & 0.015 \\
\hline Grunting & 8 & 2.6 & 12 & 7.5 & 0.015 \\
\hline Wheezing & 85 & 28.1 & 65 & 40.4 & 0.007 \\
\hline Crackles & 107 & 66.5 & 130 & 61.9 & 0.846 \\
\hline \multicolumn{6}{|l|}{ X-ray findings } \\
\hline Interstitial markings & 95 & 32.4 & 64 & 40.8 & 0.078 \\
\hline Hyperinflation & 61 & 20.8 & 43 & 27.4 & 0.115 \\
\hline Atelectasis & 36 & 12.3 & 29 & 18.5 & 0.075 \\
\hline Peribronchial thickening & 101 & 34.5 & 62 & 39.5 & 0.291 \\
\hline Consolidation & 63 & 21.5 & 27 & 17.2 & 0.277 \\
\hline Normal X-ray findings & 112 & 38.2 & 55 & 35 & 0.504 \\
\hline Leukocytosis & 82 & 27.6 & 42 & 26.3 & 0.826 \\
\hline \multicolumn{6}{|l|}{ Outcomes } \\
\hline ICU admission & 36 & 11.9 & 13 & 8.1 & 0.200 \\
\hline Death & 3 & 1.0 & 0 & 0.0 & 0.205 \\
\hline Length of stay, mean (SD) & \multicolumn{2}{|c|}{$3.6(2.6)$} & \multicolumn{2}{|c|}{$3.5(2.2)$} & 0.589 \\
\hline Severity & & & & & 0.171 \\
\hline Not severe & 212 & 70.2 & 103 & 64.0 & \\
\hline Severe & 90 & 29.8 & 58 & 36.0 & \\
\hline
\end{tabular}

Abbreviations: ALRI, acute lower respiratory infection; ICU, intensive care unit; RSV, respiratory syncytial virus; SD, standard deviation; SpO 2 , oxygen saturation.

Note: The demographic and clinical characteristics of RSV-positive ALRI patients were compared with those of RSV-negative ALRI patients using the chi-square test. A $p$-value of $<0.05$ was considered statistically significant.

${ }^{a}$ Value in bold is statistically significant ( $p$-value $\left.<0.05\right)$

\section{Factors Associated with Length of Stay}

A history of prematurity, the presence of a chronic illness, $\mathrm{SpO}_{2}<90 \%$, and the presence of atelectasis and consolidation on chest X-rays were significantly associated with a longer mean LoS ( - Table 3). Although patients infected with HMPV or HAdV had a longer mean of LoS than those of other patients, the differences were not significant $(p=0.308)$. The analysis of RSV-positive ARI patients revealed that disease severity was the only significant predictive factor for increased LoS. The mean LoS was 4.5 days for RSV-positive patients with severe disease in comparison to 2.9 days for RSV-positive patients with nonsevere disease $(p<0.005)$.

\section{Factors Associated with Severe ALRI}

- Table 4 shows the multivariate analysis of the factors associated with severe ALRI. Patients with a history of prematurity had higher odds of severe ALRI (odds ratio [OR] $=2.6$ ) compared with patients who were full-term. Patients admitted to KAUH $(\mathrm{OR}=5.6)$ and those who did not attend daycare $(\mathrm{OR}=2.8)$ were more likely than patients admitted to $\mathrm{PRH}$ and those who attended daycare, respectively, to have a severe form of the disease. The majority of children enrolled did not attend daycare $(92.7 \%, p=0.000)$, and almost half of those (54.3\%) were younger than 6 months. Compared with patients aged younger than 6 months, those aged 6.1 to 12 months were significantly less likely to have severe ALRI. HMPV-positive ALRI was significantly associated with an increased risk of severe disease. In RSV-positive patients, prematurity was the only significant predictive factor for severe ALRI ( $O R=6.4 ; 95 \%$ confidence interval: 2.4, 17.6; $p<0.005)$. Among children aged 6.1 to 12 months, compared with children who were not exclusively breastfed, those who had significantly had less severe disease $(p=0.046)$.

\section{Discussion}

In this cohort in Northern Jordan during the winter of 2016, RSV was the most common viral cause of ARI/ALRI-associated hospitalization, following the global trend of RSV being the most common viral etiology of ARI in children less than 5 years old. ${ }^{2,3,8-10}$ Thus, RSV imposes a burden on the limited health care resources of Jordan. Furthermore, this 
8 Viral Surveillance of Children with Acute Respiratory Infection Awad et al.

Table 3 Multivariate analysis of factors associated with length of stay in the whole cohort

\begin{tabular}{|l|l|l|}
\hline & $\begin{array}{l}\text { Mean length } \\
\text { of stay (95\% } \\
\text { confidence } \\
\text { interval) }\end{array}$ & p-Value ${ }^{\text {a }}$ \\
\hline Gestational age & & $\mathbf{0 . 0 0 3}$ \\
\hline Full-term & $5.1(4.5,5.8)$ & \\
\hline Premature & $6.2(5.4,7.0)$ & \\
\hline Chronic disease & & $\mathbf{0 . 0 1 5}$ \\
\hline No & $5.3(4.6,5.9)$ & \\
\hline Yes & $6.0(5.3,6.7$ & \\
\hline SpO & & $\mathbf{0 . 0 0 0}$ \\
\hline$>94$ & $4.4(3.9,4.9)$ & \\
\hline $90-94$ & $5.1(4.0,6.1)$ & \\
\hline$<90$ & $7.2(6.4,8.0)$ & \\
\hline Atelectasis & & $\mathbf{0 . 0 2 4}$ \\
\hline No & $5.3(4.7,5.9)$ & \\
\hline Yes & $6.0(5.3,6.7)$ & \\
\hline Consolidation & $5.4(4.8,6.0)$ & $\mathbf{0 . 0 0 3}$ \\
\hline No & $5.2(4.6,5.8)$ & \\
\hline Yes & $6.1(5.3,6.8$ & \\
\hline Presence of viruses & $6.3(5.2,7.4)$ & \\
\hline No virus & $6.3(4.8,7.7)$ & \\
\hline RSV & $5.1(4.3,5.9)$ & \\
\hline Rhinovirus & & \\
\hline Metapneumovirus & & \\
\hline Adenovirus & & \\
\hline RSV and another virus & & \\
\hline & & \\
\hline
\end{tabular}

Abbreviations: $\mathrm{RSV}$, respiratory syncytial virus; $\mathrm{SpO}_{2}$, oxygen saturation. Note: Multivariate analysis of factors associated with length of stay in the whole cohort was conducted using general linear model (GLM).

${ }^{a}$ Value in bold is statistically significant ( $p$-value $<0.05$ ).

finding was in line with the results observed in other countries in the Middle East, such as Qatar, Saudi Arabia, and Oman, which all identified RSV as the primary viral cause of ARI in children. ${ }^{23-25}$ The study period was during the peak of RSV infection based on what has been reported about the seasonality of RSV in temperate climates. ${ }^{7}$

HRV was the second most commonly detected virus after RSV, which was similar to the results of the viral surveillance study in Amman conducted by Halasa et al. ${ }^{18}$ HRV was comparable to RSV with regard to the clinical presentation and disease severity. Therefore, HRV contributes to the burden of ARI in young children, which was also reported previously. ${ }^{26}$

HMPV was the third most common virus causing ARI and was significantly associated with the severity of ALRI in the multivariate analysis. This finding is consistent with the results of the study conducted in Amman, in which HMPV was found to cause ALRI in $8.6 \%$ of the hospitalized children, with a peak of infection from February until April and was
Table 4 Multivariate analysis of factors associated with severe ALRI

\begin{tabular}{|c|l|l|l|}
\hline & OR & $\begin{array}{l}\text { 95\% } \\
\text { confi- } \\
\text { dence } \\
\text { interval }\end{array}$ & p-Value ${ }^{\mathrm{a}}$ \\
\hline $\begin{array}{l}\text { Gestational age (pre- } \\
\text { mature vs. full-term) }\end{array}$ & 2.6 & $1.5,4.7$ & $\mathbf{0 . 0 0 1}$ \\
\hline Daycare (no vs. yes) & 2.8 & $7.3,1.0$ & $\mathbf{0 . 0 4 2}$ \\
\hline Hospital (KAUH vs. PRH) & 5.6 & $9.4,3.3$ & $\mathbf{0 . 0 0 0}$ \\
\hline Age (months) & & & \\
\hline$\leq 6$ & 1.0 & & \\
\hline $6.1-12$ & 0.4 & $0.2,0.7$ & $\mathbf{0 . 0 0 1}$ \\
\hline $12.1-24$ & 0.7 & $0.4,1.3$ & 0.274 \\
\hline$>24$ & 0.5 & $0.2,1.0$ & 0.061 \\
\hline $\begin{array}{l}\text { Metapneumovirus- } \\
\text { positive }\end{array}$ & 3.5 & $1.6,7.6$ & $\mathbf{0 . 0 0 2}$ \\
\hline
\end{tabular}

Abbreviations: ALRI, acute lower respiratory infection; KAUH, King Abdullah University Hospital; OR, odds ratio; PRH, Princess Rahmah Hospital.

Note: The risk factors of severe disease presentation were analyzed with binary logistic regression. The variables were included in the model stepwise, and those with $p<0.10$ in the univariate analysis were included in the multivariate risk factor model of risk factors. A $p$-value of $<0.05$ was considered statistically significant.

${ }^{a}$ Value in bold is statistically significant ( $p$-value $<0.05$ ).

found to be an independent risk factor for severe disease presentation. ${ }^{27} \mathrm{HMPV}$ is a known viral cause of ALRI in young children and has been previously associated with severe disease. Edwards et al $^{28}$ demonstrated a significant association between HMPV infection in hospitalized children and increased supplemental oxygen use and ICU LoS.

Coinfection with other viruses was not uncommon. The presence of HRV or HMPV with RSV did not increase the LoS or the severity of the illness, which was consistent with the findings of other studies. ${ }^{29,30}$ In contrast, RSV infection alone was associated with an increased risk of ICU admission compared with children coinfected with RSV and HMPV. Compared with patients in older age classes, younger patients had an increased risk of RSV-associated hospitalization and increased severity of the disease. This finding is in agreement with the results of previous studies that reported that younger age is associated with a higher risk of severe RSV-associated disease and hospitalizations. ${ }^{3,8,31-33}$ Moreover, compared with RSV-negative children, RSV-positive children were more likely to have a higher respiratory rate, retraction, flaring, grunting, and wheezing, which are indicative of a more severe presentation.

Previous studies identified multiple risk factors for RSVassociated hospitalization and disease severity; these risk factors included being male, prematurity, having chronic lung disease, the lack of breast feeding, daycare attendance, living with other siblings, exposure to smoke, and having a chronic illness. ${ }^{3,11,31,33-45}$ This study found no difference in the risk of RSV hospitalization according to gender as 
reported previously. ${ }^{3,31}$ Prematurity did not increase the risk of RSV infection, which may be explained by the fact that all premature infants in this study were late-preterm (>29-36 weeks). It has been reported that late-preterm infants have a lower risk of RSV acquisition than early-preterm infants. ${ }^{3,31,45}$ Prematurity, however, increased the severity of both RSV-positive and RSV-negative ALRI, as well as the LoS in the entire cohort. Chronic lung disease increased the risk of RSV infection and RSV-associated ALRI; however, it was not a risk factor for increased severity in our study. When exclusively breastfed children were compared with the nonexclusively breastfed children, the former had significantly less severe ALRI which is consistent with the previously reported protection of breast feeding being related to exclusiveness. ${ }^{46}$ Nishimura et al also demonstrated a difference in the LoS and oxygen use according to breast feeding being partial or full. ${ }^{47}$ The lack of daycare attendance was a risk factor for increased severity, which could be attributed to the majority of children (92.7\%) not attending daycare in this cohort. This was also confounded by the fact that of those who did not attend daycare, almost half were below the age of 6 months, which is the age group with more severe disease than was found in older patients. Patients admitted to KAUH rather than PRH had more severe disease presentation, which can be attributed to KAUH being a referral hospital, making this observation expected.

Notably, chest imaging was ordered in almost all admitted cases (97\%) reflecting a lack of adherence to the international guidelines regarding chest radiography indications in young children with ALRI. ${ }^{40,42}$ The presence of atelectasis and consolidation were significantly related to increased LoS. In an outpatient study performed by Shaw et al, atelectasis was also associated with the severity of ALRI. ${ }^{48}$ Consolidation can also be attributed to secondary bacterial infection which was not tested in this study population.

There are multiple limitations of this study. First, the presence of bacteria was not tested, and secondary bacterial infection could influence the clinical presentation and outcome. Second, the surveillance was limited to the winter season, potentially underestimating the burden of the disease and the seasonality of RSV infection. Third, there was a lack of testing for influenza A and B viruses which have implications in patients hospitalized with ALRI in Jordan as has been extensively studied previously. ${ }^{49}$

\section{Conclusion}

This study is the first prospective surveillance study showing the significant burden of ARI/ALRI-associated hospitalization caused by viruses during the winter season in Irbid, Northern Jordan, using a sensitive detection to estimate the burden of the illness in the nation of Jordan and contribution to the epidemiological data regarding viral ARI in young children in the Middle East. RSV was identified as the most common viral cause of ARI. Other viruses, such as HMPV, should be considered as the etiology for severe ALRI. Risk factors for increased LoS and severe disease presentation of ALRI were determined in the population of Northern Jordan. Exclusive breast feeding was essential in decreasing the severity of ALRI. These findings are crucial for stakeholders in the health care system, to prioritize health care interventions, particularly in settings with limited resources. Laboratory confirmation of viral etiology would help minimize antibiotic use in managing ARI. This study may also aid measures to implement future strategies for RSV vaccination when available.

\section{Ethical Approval}

This study was approved by the Institutional Review Board of Jordan University of Science and Technology, reference number: 28/91/2015.

\section{Funding}

This work was supported by the Deanship of Research at Jordan University of Science and Technology under grant number: 20150367.

\section{Conflict of Interest}

None declared.

\section{References}

1 Walker CLF, Rudan I, Liu L, et al. Global burden of childhood pneumonia and diarrhoea. Lancet 2013;381(9875):1405-1416

2 Nair H, Nokes DJ, Gessner BD, et al. Global burden of acute lower respiratory infections due to respiratory syncytial virus in young children: a systematic review and meta-analysis. Lancet 2010; 375(9725):1545-1555

3 Hall CB, Weinberg GA, Iwane MK, et al. The burden of respiratory syncytial virus infection in young children. N Engl J Med 2009;360 (06):588-598

4 Shi T, McAllister DA, O’Brien KL, et al; RSV Global Epidemiology Network. Global, regional, and national disease burden estimates of acute lower respiratory infections due to respiratory syncytial virus in young children in 2015: a systematic review and modelling study. Lancet 2017;390(10098):946-958

5 Shi T, McLean K, Campbell H, Nair H. Aetiological role of common respiratory viruses in acute lower respiratory infections in children under five years: a systematic review and meta-analysis. J Glob Health 2015;5(01):010408

6 Ruuskanen O, Lahti E, Jennings LC, Murdoch DR. Viral pneumonia. Lancet 2011;377(9773):1264-1275

7 Horton KC, Dueger EL, Kandeel A, et al. Viral etiology, seasonality and severity of hospitalized patients with severe acute respiratory infections in the Eastern Mediterranean Region, 2007-2014. PLoS One 2017;12(07):e0180954

8 Nokes DJ, Cane P. Respiratory Syncytial Virus Disease Burden in the Developing World. In: Perspectives in Medical Virology: Respiratory Syncytial Virus. 14th ed. Elsevier; 2007:183-230

9 Peltola V, Ruuskanen O. Editorial commentary: respiratory viral infections in developing countries: common, severe, and unrecognized. Clin Infect Dis 2008;46(01):58-60

10 Haynes AK, Manangan AP, Iwane MK, et al. Respiratory syncytial virus circulation in seven countries with Global Disease Detection Regional Centers. J Infect Dis 2013;208(Suppl 3):S246-S254

11 American Academy of Pediatrics Committee on Infectious Diseases; American Academy of Pediatrics Bronchiolitis Guidelines Committee. Updated guidance for palivizumab prophylaxis among infants and young children at increased risk of hospitalization for respiratory syncytial virus infection. Pediatrics 2014; 134(02):e620-e638

12 Modjarrad K, Giersing B, Kaslow DC, Smith PG, Moorthy VS; WHO RSV Vaccine Consultation Expert Group. WHO consultation on 
Respiratory Syncytial Virus Vaccine Development Report from a World Health Organization Meeting held on 23-24 March 2015. Vaccine 2016;34(02):190-197

13 Henrickson KJ, Hall CB. Diagnostic assays for respiratory syncytial virus disease. Pediatr Infect Dis J 2007;26(11, Suppl):S36-S40

14 Khuri-Bulos N, Williams JV, Shehabi AA, et al. Burden of respiratory syncytial virus in hospitalized infants and young children in Amman, Jordan. Scand J Infect Dis 2010;42(05): 368-374

15 Kaplan NM, Dove W, Abd-Eldayem SA, Abu-Zeid AF, Shamoon HE, Hart CA. Molecular epidemiology and disease severity of respiratory syncytial virus in relation to other potential pathogens in children hospitalized with acute respiratory infection in Jordan. J Med Virol 2008;80(01):168-174

16 Miller EK, Khuri-Bulos N, Williams JV, et al. Human rhinovirus C associated with wheezing in hospitalised children in the Middle East. J Clin Virol 2009;46(01):85-89

17 Ali SA, Williams JV, Chen Q, et al. Human metapneumovirus in hospitalized children in Amman, Jordan. J Med Virol 2010;82(06): 1012-1016

18 Halasa N, Williams J, Faouri S, et al. Natural history and epidemiology of respiratory syncytial virus infection in the Middle East: hospital surveillance for children under age two in Jordan. Vaccine 2015;33(47):6479-6487

19 Bradley JS, Byington CL, Shah SS, et al. Executive summary: the management of community-acquired pneumonia in infants and children older than 3 months of age: clinical practice guidelines by the Pediatric Infectious Diseases Society and the Infectious Diseases Society of America. Clin Infect Dis 2011;53(7): 617-630

20 AmpliSens ${ }^{\circledR}$ ARVI-screen-FRT. AmpliSens ARVI-screen-FRT PCR kit Instruction Manual. Available at: http://www.interlabservice. ru/upload/iblock/de8/ARVI-screen-FRT (R-V57-100-F(RG,iQ,Dt)CE)_270617.pdf. Accessed August 31, 2017

21 Preterm birth. Available at: https://www.who.int/news-room/ fact-sheets/detail/preterm-birth. Accessed March 5, 2019

22 Organization WH. International Statistical Classification of Diseases and Related Health Problems. Tenth Revision. 2nd ed. World Health Organization; 2004 Low Birth Weight. Available at: https:// www.who.int/classifications/icd/en/. Accessed March 5, 2019

23 Janahi I, Abdulkayoum A, Almeshwesh F, Alkuwari M, Al Hammadi A, Alameri M. Viral aetiology of bronchiolitis in hospitalised children in Qatar. BMC Infect Dis 2017;17(01):139

24 Amer HM, Alshaman MS, Farrag MA, Hamad ME, Alsaadi MM, Almajhdi FN. Epidemiology of 11 respiratory RNA viruses in a cohort of hospitalized children in Riyadh, Saudi Arabia. J Med Virol 2016;88(06):1086-1091

25 Khamis FA, Al-Kobaisi MF, Al-Areimi WS, Al-Kindi H, Al-Zakwani I. Epidemiology of respiratory virus infections among infants and young children admitted to hospital in Oman.J Med Virol 2012;84 (08):1323-1329

26 Toivonen L, Schuez-Havupalo L, Karppinen S, et al. Rhinovirus infections in the first 2 years of life. Pediatrics 2016;138(03): e20161309-e20161309

27 Schuster JE, Khuri-Bulos N, Faouri S, et al. Human metapneumovirus infection in Jordanian children: epidemiology and risk factors for severe disease. Pediatr Infect Dis J 2015;34(12):1335-1341

28 Edwards KM, Zhu Y, Griffin MR, et al; New Vaccine Surveillance Network. Burden of human metapneumovirus infection in young children. N Engl J Med 2013;368(07):633-643

29 Martin ET, Kuypers J, Wald A, Englund JA. Multiple versus single virus respiratory infections: viral load and clinical disease severity in hospitalized children. Influenza Other Respir Viruses 2012; 6(01):71-77

30 Chorazy ML, Lebeck MG, McCarthy TA, Richter SS, Torner JC, Gray GC. Polymicrobial acute respiratory infections in a hospital- based pediatric population. Pediatr Infect Dis J 2013;32(05): 460-466

31 Hall CB, Weinberg GA, Blumkin AK, et al. Respiratory syncytial virus-associated hospitalizations among children less than 24 months of age. Pediatrics 2013;132(02):e341-e348

32 Fryzek JP, Martone WJ, Groothuis JR. Trends in chronologic age and infant respiratory syncytial virus hospitalization: an 8-year cohort study. Adv Ther 2011;28(03):195-201

33 Stein RT, Bont LJ, Zar H, et al. Respiratory syncytial virus hospitalization and mortality: systematic review and meta-analysis. Pediatr Pulmonol 2017;52(04):556-569

34 Rossi GA, Medici MC, Arcangeletti MC, et al; Osservatorio RSV Study Group. Risk factors for severe RSV-induced lower respiratory tract infection over four consecutive epidemics. Eur J Pediatr 2007;166(12):1267-1272

35 von Linstow M-L, Høgh M, Nordbø SA, Eugen-Olsen J, Koch A Høgh B. A community study of clinical traits and risk factors for human metapneumovirus and respiratory syncytial virus infection during the first year of life. Eur J Pediatr 2008;167(10): $1125-1133$

36 Bradley JP, Bacharier LB, Bonfiglio J, et al. Severity of respiratory syncytial virus bronchiolitis is affected by cigarette smoke exposure and atopy. Pediatrics 2005;115(01):e7-e14

37 Langley GF, Anderson LJ. Epidemiology and prevention of respiratory syncytial virus infections among infants and young children. Pediatr Infect Dis J 2011;30(06):510-517

38 Greenough A, Cox S, Alexander J, et al. Health care utilisation of infants with chronic lung disease, related to hospitalisation for RSV infection. Arch Dis Child 2001;85(06):463-468

39 Liese JG, Grill E, Fischer B, Roeckl-Wiedmann I, Carr D, Belohradsky BH; Munich RSV Study Group. Incidence and risk factors of respiratory syncytial virus-related hospitalizations in premature infants in Germany. Eur J Pediatr 2003;162(04):230-236

40 Meissner HC. Viral bronchiolitis in children. N Engl J Med 2016; 374(18):1793-1794

41 Shi T, Balsells E, Wastnedge E, et al. Risk factors for respiratory syncytial virus associated with acute lower respiratory infection in children under five years: systematic review and meta-analysis. J Glob Health 2015;5(02):020416

42 Ralston SL, Lieberthal AS, Meissner HC, et al; American Academy of Pediatrics. Clinical practice guideline: the diagnosis, management, and prevention of bronchiolitis. Pediatrics 2014;134(05): e1474-e1502

43 Sommer C, Resch B, Simões EAF. Risk factors for severe respiratory syncytial virus lower respiratory tract infection. Open Microbiol J 2011;5(01):144-154

44 Simoes EAF. Environmental and demographic risk factors for respiratory syncytial virus lower respiratory tract disease. J Pediatr 2003;143(5, Suppl):S118-S126

45 Stevens TP, Sinkin RA, Hall CB, Maniscalco WM, McConnochie KM. Respiratory syncytial virus and premature infants born at 32 weeks' gestation or earlier: hospitalization and economic implications of prophylaxis. Arch Pediatr Adolesc Med 2000;154(01): 55-61

46 Dornelles CTL, Piva JP, Marostica PJC. Nutritional status, breastfeeding, and evolution of infants with acute viral bronchiolitis. J Health Popul Nutr 2007;25(03):336-343

47 Nishimura T, Suzue J, Kaji H. Breastfeeding reduces the severity of respiratory syncytial virus infection among young infants: a multi-center prospective study. Pediatr Int 2009;51(06):812-816

48 Shaw KN, Bell LM, Sherman NH. Outpatient assessment of infants with bronchiolitis. Am J Dis Child 1991;145(02):151-155

49 Al-Abdallat M, Dawson P, Haddadin AJ, et al. Influenza hospitalization epidemiology from a severe acute respiratory infection surveillance system in Jordan, January 2008-February 2014. Influenza Other Respir Viruses 2016;10(02):91-97 